\title{
The Solution of a Clothing Mass Customization Program
}

\author{
Jocelyn BELLEMARE* \\ Ecole Polytechnique of Montreal, Departement of Industrial Engineering, Montreal (QC), Canada
}

\begin{abstract}
Consumers are better educated and more demanding nowadays. They're no longer satisfied with standardized products that force them to compromise. It may be as small as a change in color or it could be a change in the functionality of the product. To meet customer expectations, clothing companies now have to manufacture or offer made-to-measure products. Brands that offer mass customization products are spreading through traditional businesses as well as the Web. In the clothing industry, some companies have successfully applied mass customization principles to their formerly standardized products.
\end{abstract}

The mass customization, as a business strategy, is an evolving concept in apparel industry intended to provide customized products through agile and flexible processes in high volumes and at sensibly low costs. Companies need to realize the degree of customization valued by the customers and the extent of customization that can be offered competitively. It is a challenge to the apparel industry to maintain a profitable business and still satisfy the customer. However, mass customization is not generally well understood or implemented by companies, due to problems related to measurements, pattern adaptation, and inflexible manufacturing methods and lead times. The developments in new technologies, such as 3-dimensional body scanning and digital printing, have the potential of enabling manufacturers to utilize mass customization business strategies that would allow them to more effectively meet the needs of specific customers

This research project offers many possibilities for innovation and could constitute a major opportunity for certain players in the clothing industry. If prime producers want to seize the moment, they will have to better understand what is feasible in clothing mass customization. This understanding will enable them to devise a measurement configurator strategy that will create opportunities for more effective market segmentation, and thus help develop a new competitive advantage.

Keywords: Mass Customization, Sticky informations, Product configurator, Apparel industry

\section{Introduction}

The clothing industry is currently undergoing a period of turmoil due in large part to globalization. This industry represents an important source of economic activity and employment. Montreal is Canada's leader in the clothing sector and also ranks amongst the most important clothing manufacturing centres in North America (with Los Angeles and New York ${ }^{1}$ ). Following sustained growth in the 1990s, the industry is currently experiencing disruptions as a result of massive imports and economic variations in its market.

Significant breakthroughs by foreign new comers in the industry add to the existing local competition. As a result, Quebec businesses must face unprecedented rivalry. As products now seem to have an ever shorter life cycle, a phenomenon which is exacerbated by the introduction and implementation of new business models, businesses' commercial strategies must face mounting pressure, most notably for those involved in the sectors of fashion, textiles and clothing. This situation forces players in the Quebec industry to revise their organizational strategies in order to survive in this highly competitive market.

Solutions to these problems can mainly be found in the corporate strategies (namely, in commercial and manufacturing strategies) of the Quebec businesses that are being threatened. These

\footnotetext{
1 Fashion and Clothing Industry Strategy, Minister of Economic Development, Innovation and Export Trade, Department of consumer goods - Quebec Report (2008)

* bellemare.jocelyn@uqam.ca; +1- 514-933-6988
} 
companies must try to reinvent themselves and find new ways to satisfy their customers. In order to grow, to maintain the current level of employment and possibly to increase it, prime producers will need to develop new manufacturing strategies by orienting local production towards a flexible, quick-response system that allows for the production of various types of orders (small quantities, short deadlines, skilled labour, etc.). Thus, it will become essential for businesses to implement new strategies that correspond to the reality of current markets, in order to keep up with the rhythm of short cycle production. Businesses need focus on flexibility, adaptability and agility (Pine, 1993).

In an age where innovation and technological developments play an increasingly crucial role in counteracting the effects of lower wages found in other countries, the objective of this research is to demonstrate the importance of implementing mass customization manufacturing systems adapted to the needs of all actors in the clothing industry. Even though the local garment industry and that of emerging countries face each other on an uneven playing field, the local industry possesses a technological environment that could give it a significant advantage.

\section{Research}

With the recent surge in the use of new media and telecommunication, consumers are more and more demanding and informed. They are no longer satisfied with standardized products that force them to make compromises. The Internet influences customers' buying habits by creating needs that have to be satisfied instantaneously.

In the clothing industry, these expectations not only imply having to constantly provide consumers with new options in terms of styles and colours, but also to allow them to find an affordable close-fitting clothing item and make it available to them almost as rapidly as if it was a standard-sized product. In order to meet these expectations, clothing companies must now propose custom-made products. Brands that offer personalized products (mass customization) are taking over both traditional and online stores. This is made possible by identifying the key points of measurement necessary to produce well adjusted, close-fitting garments. However, being able to take these measurements efficiently and effectively is crucial.

Although efficient and affordable technologies are available to provide a Body Scan, few businesses are able to meet the requirements of custom-made products for the following reasons:

(1) Lack of reliability of the measures provided by the Body Scan

(2) Problems related to the transmission of a large quantity of data to potential manufacturers

(3) Interface issues between the data generated by the Body Scan software and that used by pattern making, cutting and assembly.

In the apparel industry, some corporations (Levis, Nike) have successfully implemented mass customization principles to products that were thus far standardized. Even designers such as Jean-Charles de Castelbajac and Longchamp have played the role of pioneers in the luxury goods market by offering, respectingly, prêt-à-porter and customizable bags.

Nevertheless, mass customization somehow remains misunderstood or is rarely used by actors in the clothing industry mainly because of the widely variable measurements, of the problems in adapting patterns, of the need for flexibility of manufacturing delays and methods.

Many authors have produced research on mass customization; however, few of them have sought to identify the problems related to sizing and to so-called 'hidden data' coming from the customers (ease allowance, fulness, etc.)

\subsection{General objectives}

The general aim of this project is to develop a configurator, using computerized information systems, that could be used to analyze and decode measurement data coming from peripheral devices in order to identify as precisely as possible. 


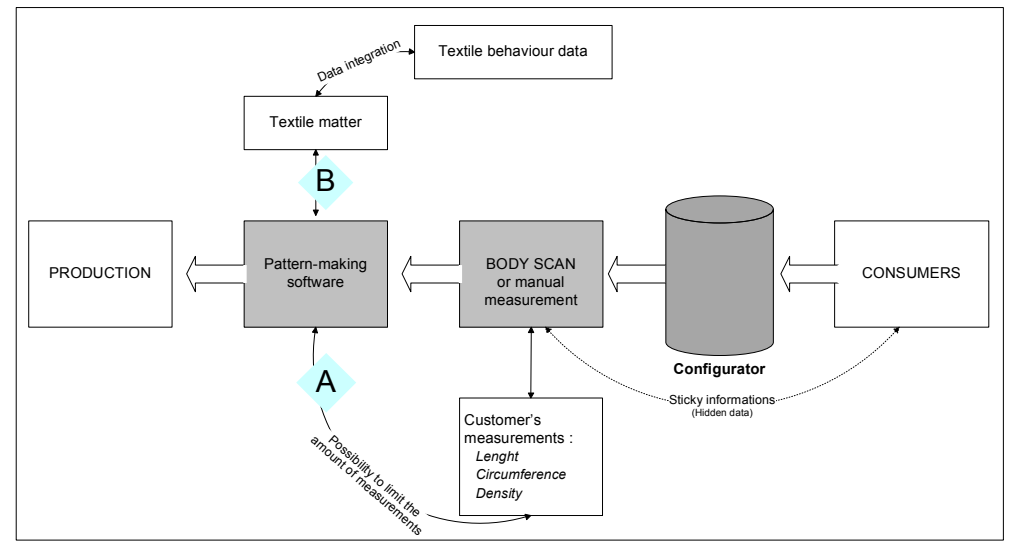

Fig. 1. Configurator for Clothing Mass Customization

In this context, the specific objective of this research project is to identify the fundamental variables and data that are necessary to produce custom-made clothing. The reduction of the number of fundamental variables (length, circumference, density and textile matter behaviour) will allow to significantly diminish the amount of data to analyze and send out in order to create an 'intelligent' pattern. We consider, in our hypothesis, that the amount of non-essential data for pattern automation can be reduced by $65 \%$, if compared to current situation in the garment industry. In this research, we will not only try to reduce the quantity of data, but also to determine the minimal number of measures needed (minimum cardinalities). Moreover, using anthropometric measurements, like density, will enable us to identify key referential points which are essential to ensure proper fit. These referential points, when combined with data related to textile textures and behaviours, will allow for personalized pattern grading.

This research project therefore aims at reducing the amount of data while increasing the quality of automated clothing patterns, thereby allowing for the production of well adjusted custom-made clothing that meet customers' needs and expectations.

\section{Literature}

Paradoxically, in an age where standardization is ubiquitous at an international level, the current catch phrase in the fashion world is: unique. Nevertheless, the confusion between personalization and mass customization still reigns. Inala (2007) contends that mass customization has become a competitive strategy for businesses that want to offer personalized products. The more a business provides opportunities to personalize its products, the more competitive it becomes (Pine, 1993). When clothing was made-to-measure, each one was cut and assembled for individual customers (Istook 2002). As a result, it provided a personalized fit (Workman, 1991). This type of production is what Pine (1993) refered to as personalized and handcrafted production. However, in order to be able to meet the demands of mass customization, all of a manufacturer's operations have to be based, according to Zipkin (2001), on flexible processes that allow it to respond rapidly to customers' requests. More often than not, mass customization consists in, for example, assembling basic items according to specific orders.

Fashion being first and foremost relatively subjective, customers are inscreasingly focused on their own requirements and, consequently, more resistant to product standardization (Wang, Zhou et Zhang, 2009). Mass customization therefore becomes a crucial development solution for businesses specialized in garment manufacturing and the distribution (Pine, 1993). In fact, the demand for mass customization of clothing is only growing stronger. It has become possible thanks to the contribution of new technologies. Custom-made clothing requires a very thorough understanding of the expectations and specificities of each individual (Peterson, 2008). According to Pine (1993), the success of mass customization rests mainly on a successful integration of the value chain. In some respects, businesses must accomplish a feat by performing well on two (2) axis that are generally on opposite sides of the spectrum in most bussinesses: maintaining short supplying lead times while offering custom-made products that correspond to clients' specifications. 


\subsection{The problems of mass customization}

Agrawal, Kumaresh and Mercer (2001) indicate that the main problem of mass customization is related to the preparation of products according to customers' requirements. Von Hippel (1998) states that because of their lack of knowledge and experience, consumers do not know what they really want. It is thus important to simplify their request by offering them some guidance. Doing so not only requires knowing a customer's measurements and style, but also obtaining information that he never reveals: what literature refers to as "sticky information". The term "sticky information" is defined by Von Hippel (1994) as information hidden by a customer that provides, in certain cases, a company with a key competitive advantage and offers significant opportunities for innovation. For example, consumers know their needs and tastes better than manufacturers. It is therefore difficult for a manufacturer to obtain information that is either confidential or perceived to be so irrelevant that consumers reveal them sporadically, at best. This unknown data, like ease allowance, fit, proportion and the like, are essential to the production of custom-made goods. According to Ashdown (2007), they are at the source of most purchase returns occurring in stores.

In the American industry, clothing size standards were created following anthropometric studies conducted in the 1940s. The aim was to satisfy customers by allowing manufacturers to fine-tune their production in terms of sizing. Today in Canada, the government (through the Canadian General Standards Board) provides a code for each size which corresponds to specific body and clothing measurements. For men's apparel, the CGSB has been using the size chart that was introduced in the U.S.A. in the 1950s. In recent years, however, we have come to face certain problems related to fitting. Body proportions have changed since the 1940s and 1950s, or even since the 1980s. According to Norman Marks : "Body measurements of Quebeckers have changed: clothing sizes based on body measurements established in the 1980s no longer correspond to reality. The new generation of men between 18 and 35 is much taller than the average height found in the 1980s."

Workman (1991), for example, indicates that the average height of men living in the United States in 1940 was 1,69 meters, compared to 1,76 meters today. Furthermore, according to Yunchu, Weiyuan and Cong (2007), effects related to nutrition and physical exercise have modified ergonomics body which make clothing adjustments more complicated. Following a study in collaboration with Size Germany, Melliand (2005) asserts that the average physical stature of men has increased by $16 \mathrm{~cm}$ since 1875. As a result, today's table of standard measurements for sizes 36 to 46 is no longer correctly adjusted. Standard sizing issues for clothing are only becoming more widespread with the advent of globalization (Faust, 2009). Because of this, order initiators do not respect standards and create their own size specifications that correspond to their target market or are consistent with their vanity sizing strategy. However, they still continue to use the generally accepted size values (Ulrich, Anderson-Connell and Wu, 2003). Without clearly established norms or standards, consumers are having difficulties finding their way, which generates frustration and confusion when trying on clothes.

Norman Marks confirms: "In the past, the best selling two-piece suit was made of a size 40 jacket and size 33/34 trousers. Nowadays, the same suit with size 34 trousers will be offered to this new generation of customers with a size 42 , or even 44 , jacket." For businesses, manufacturer's clothing sizes are inconsistent and can create important losses in terms of potential sales, according to Workman (1991).

The increase in purchase returns for clothes both in stores and on the Web creates headaches for retailers because it bears some consequences on their brand image (Park and Stoel, 2002). According to a survey conducted by Synovate in $2008,58 \%$ of Canadians claim that it is very difficult to find clothes that fit them perfectly and $77 \%$ of people surveyed find that sizes vary from store to store. As a result, it appears important for stores to know their clientele and to offer clothes that fit customers adequately in order to increase their volume of sales per customer. Thus, some problems associated with mass customization must be corrected by the garment industry, they are:

a) The templates used to create basic patterns are not adequate;

b) The size standards and measurement charts have become obsolete;

c) The sizing per territory/population rapidly changes;

d) Some of the information hidden by the customer must be decoded by manufacturers

Faust (2009) contends that errors in measurements still prevail in the clothing industry. Even if a customer is given a sizing chart, it is still difficult for him to take accurate measurements on his own. Ashdown (2004) has identified a few simple problems that might be encountered. For instance, when 
measuring waist circumference, it is necessary to stand straight in a natural position and to hold the tape measure parallel to the ground. A slight imbalance could result in errors of up to half an inch on the final garment. The main problem occurs when measuring the waist girth. Norman Marks explain that some measure the narrowest part of the waist, while other use the navel or small of the back as a reference point. Yet, it seems that master tailors never need to ask themselves this question because their intrinsic knowledge and experience helps them decide how to take this rather complex measure. Moreover, Park and Stoel (2002) mention that data transmission errors taking place during the data transfer process create problems at the time of order. As for the 3D body scan technology, it sends more than 300000 data items during a sample body scan (Ashdown, 2007) which increases the complexity of selecting valid data in order to obtain reliable information.

Ashdown (2007) indicates that computer systems need to accurately generate the information coming from both the pattern-making software and from the body scan. Issues arise when size charts and fit levels for different body types are not clearly established from the start. The key to success lies in the development, the architecture and the support of computer systems used to generate data based on individual body dimensions for pattern-making software, which need to be adapted individually. Despite the fact that all these approaches aim to produce apparel as accurately as possible, it appears that the great number of constraints makes it difficult to find a compromise between performance, accuracy and technicality during the production process.

\section{The product configurator}

Configuration is an essential aspect of mass customization because it creates the possibilities to guide customers as they are making choices. Piller (2004) contends that the primary objective of a configurator is to ease the decision-making process of customers using a Web-based interface. Product configuration systems play an important role in supporting the mass customization paradigm, as it helps to determine the degree of personalisation that a business will offer. Thus, the role of the configurator is to create a link between consumers and manufacturers (Inala, 2007). Mass customization does not equate to an increase in costs. According to Pillier and Moser (2006), using a configurator could significantly reduce costs since its Web-based technolgy dimishes the time required to take orders. Figure 3 demonstrates how the configurator would operate in a clothing mass customization program:

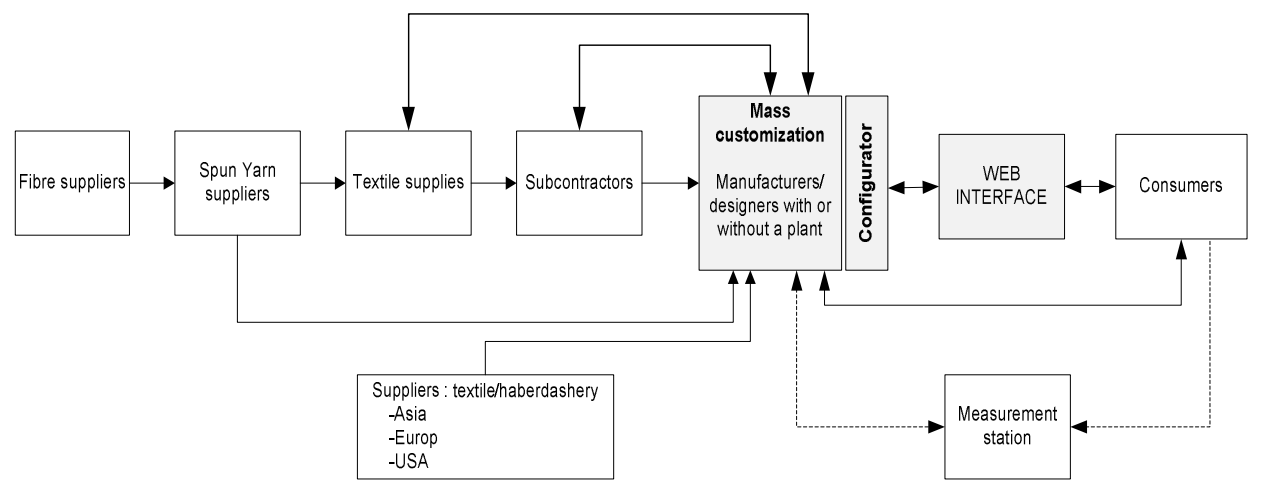

Fig. 2. Mass Customization Configurator for apparel industry

A product configurator must be used along with a high-performance technological platform so as to allow for interaction between customer and manufacturer as the product is designed. This creates an interface between the customer and the supplier which provides opportunities for value co-creation in both the apparel and fashion industries.

\subsection{Issues with configurators}

In the current context, businesses use catalogs and manual production methods. Catalogs provide a predefined and limited number of combinations for a product without necessarly fulfilling all of a customer's specific needs (Quin and Yang, 2009). Manual configuration, on the other hand, essentially relies on human expertise and necessitates competent and highly skilled workers (Rogoll and Pillier, 2004). However, a lack of expertise eventually requires investments in terms of time and efforts; moreover, it forces employees to keep up to date with frequent technical changes and 
improvements. As a result, the configuration of a product to meet a customer's requirements can become a complex task which gets more demanding as the number of components and options increases. When the configuration requires numerous variations, the possibility of making errors also rises which can result in production delays. The repetition of subsequent steps may be required which can be costly. Thus, Ashdown (2007) contends, mass customization creates various technical challenges that need to be overcome before mass customized garments can be produced.

The technological risks associated with a configurator project are essentially related to the development of a system that can share and process data and parameters (the parameter configurator) originating from various sources such as: the data entry tools (e.g. the Body scan), the basic garment patterns, the marker-making software, the automatic cutting table and the administrative and financial data. In short, none of the existing technological system seem to provide a solution for mass customization in the apparel industry. Rogoll and Pillier (2004) indicate that the optimal product configurator needs to create an interface between different programming languages and function entirely independently. Incidentally, these criteria add to the level of uncertainty associated to this type of installation.

\section{Methodology}

The first stage of this research project is a preliminary study of the fundamental variables and data needed to produce a custom-made garment. This first step will allow for the production of a thesis which is itself an integral part of a larger research project. The proposed approach will aim, in part, to identify the fundamental variables and data essential to the fabrication of custom-made apparel. After this thesis has been submitted, the data obtained will be analyzed and modelized which will allow for the creation of a product parameter configurator. Moreover, in the near future, we will assess the modalities of implementation of this technology and its progressive use in the fashion and garment industries.

The preliminary phase of this research project will take place in a manufacturing environment specialized in men's fashion. At first, we will study the mass production and custom-made environments that exist in this industry. Next, will will analyze three models pants provided by manufacturers specialized in athletic wear, sportswear and workwear. Each pattern will be analyzed and dissected in order to assess the fitting and grading methods used in relation to size and type of textile. From this first study, we will formulate a hypothesis on the fundamental variables needed to produce a garment using mass customization.

In order to validate the fundamental variables that will enable us to create our configurator, we will conduct a study on the process involved in body measurement (length, circumference, density and stature) using both a body scan and manual measurements. A group of 12 men will be recruited to allows us to modelize the variables and data linked to a fabrication model that is part of a real manufacturing process. So as to facilitate research based on individual shape groupings, we will use Rasband and Liechty's (2006) figure types represented by the letters $\mathrm{H}-\mathrm{O}-\mathrm{X}$ and $\mathrm{V}$ to categorize different types of silhouettes. Four groups will be made up of men (of different stature) wearing a size 40 jacket and trousers of sizes 32 to 38 . It will then be possible to validate the data through our configurator and produce garments using rapid prototyping. A thorough examination of the clothing items produced will be carried out during the fitting phases in order to analyze their "fit". This will allow us to determine which variables appear to be problematic.

Mass customization offers a new business model and growth opportunities for small manufacturing businesses and clothing companies. Indeed, from mass or large volume production, businesses in this industry will be able to profit from this value-added advantage. According to Zipkin (2001), this type of production will be possible on a large scale because new technologies will become more easily accessible. This project originated from the idea of creating the "optimal" product configurator which would have the capacity to efficiently translate customers' desires and associate them with their anthropometric and anthropomorphic characteristics. 


\section{Conclusion}

This research offers great possibilities in terms of innovation and could constitute an outstanding opportunity for several actors in the clothing industry. If prime producers want to make the most of this prospect, they will need to better understand what can be done in terms of clothing personalization and mass customization so as to formulate an appropriate strategy on how to use their measurement configurator. From the start, mass customization needs to directly involve customers in the designing and manufacturing phases. Moreover, this customization model must provide opportunities to generate savings by reducing stocks and by allowing for a better integration of all actors in the supply chain. Mass customization offers possibilies to reach, or even surpass, customers' expectations. Therefore, it needs to provide a knowledge base of consumers' needs and preferences and thus create opportunities for market segmentation.

This research project will provide tools for fashion industry businesses that will allow them to gain a competitive edge through custom-made and short lead time projects. The opportunities created by the absence of such a service or system needs to be used by businesses in this industry to reposition themselves on the garment and apparel markets, both locally and internationally. If actors in the fashion and garment industry accept this change of direction, this project could evolve into an extremely competitive business model that could represent a viable option for companies in different sectors.

\section{References}

1. Agrawal, M., Kumaresh, T. V., and Mercer, G. A. (2001), The False Promise of Mass Customization, The McKinsey Quarterly, No. 3, pp. 62-71.

2. Ashdown, S.P., Schoenfelder, L.K., Lyman-Clarke, L. (2004), Visual fit analysis from 3D scans, Abstracts of the Fiber Society 2004 Annual Meeting and Technical Conference, pp.111.

3. Ashdown, S.P.(2007), Cambridge Sizing in clothing : developing effective sizing systems for ready-to-wear clothing, Woodhead Publishing in association with The Textile Institute, Boca Raton : CRC Press, pp.384.

4. Faust, M.-E., \& Carrier, S. (2009). 3D body scanning's contribution to the use of apparel as an identity construction tool, San Diego, CA, United states.

5. Faust, M.-E., \& Carrier, S. (2009). A proposal for a new size label to assist consumers in finding well-fitting women's clothing, especially pants: An analysis of size USA female data and women's ready-to-wear pants for North american companies. Textile Research Journal, Vol. 79, No.16, pp.1446-1458.

6. Inala, K. (2007), Assessing product configurator capabilities for successful mass customization, University of Kentucky, theses.

7. Istook, C.L. (2002), Enabling mass customization: computer-driven alteration methods, International Journal of Clothing Science and Technology. Vol. 22, pp.16-24.

8. Melliand, T. (2005) . Current problems associated with body sizes of German men, Deutscher Fachverlag, Vol. 86, No. 5, pp. 372-373.

9. Park, J. H. and Stoel, L. (2002). Apparel shopping on the Internet: Information availability on US apparel merchand Web sites. Journal of Fashion Marketing and Management, Vol. 6, No. 2, pp.158-176.

10. Peterson, J. (2008). Mass customisation finds favour (clothing industry). Knitting International, Vol.114, No. 1360, pp. 36-37.

11. Piller, F. (2004), Mass customization: reflections on the state of the concept, International Journal of Flexible Manufacturing Systems, Vol. 16 No. 4, pp.313-34.

12. Piller, F., Walcher, D. (2006) Toolkits for idea competitions: a novel method to integrate users in new product development, R\&D Management, Vol. 36, No. 3(June), pp.307-318.

13. Pine, B.J. (1993), Mass Customization: The New Frontier in Business Competition, Harvard Business School Press, Boston, MA.

14. Qin, S., \& Yang, L. (2009). Fuzzy optimisation modelling for apparel fit from body scanning data mining, Tianjin, China.

15. Rasband, J., \& Liechty, E. (2006), Faboulous Fit, New York : Fairchild Publications, pp.176. 
16. Rogoll, T. and Piller, F. (2004), Product configuration from the customer's perspective: a comparison of configuration systems in the apparel industry, Proceedings of the International Conference on Economic, Technical and Organisational Aspects of Product Configuration Systems, Lyngby, June, pp.28-29.

17. Ulrich, P. V., Anderson-Connell, L. J. and Wu, W. (2003). Consumer co-design of apparel for mass customization. Journal of Fashion Marketing and Management, Vol. 7, No 4, pp.398-412.

18. Von Hippel, E. (1994). "Sticky Information" and the Locus of Problem Solving: Implications for Innovation. Management Science, 40(4), pp.429-439.

19. Von Hippel, E. (1998). Economics of product development by users: The impact of 'sticky' local information. Management Science, Vol.44, No. 5, pp.629-644.

20. Wang, Q., Zhou, T., \& Zhang, W. (2009). Study apparel Made to Measure based on 3D body scanner: Obtain the area of the characteristic sections of body to classify body types, Changsha, Hunan, China.

21. Wikström, S. (1996), The customer as co-producer, European Journal of Marketing, Vol. 30, no 4, pp.6-19.

22. Workman, J.E. (1991). Body Measurement Specifications for Fit Models as a Factor in Clothing Size Variation. Clothing and Textiles Research Journal, Vol. 10 (1), pp. 31-36.

23. Zipkin, P. (2001) The Limits of Mass Customization, Sloan Management Review, Vol. 42, pp. 81-87. 